\title{
Topographic Signatures in Aquarius Radiometer/Scatterometer Response: Initial Results
}

\author{
C. Utku ${ }^{(1)}$,D. M. Le Vine ${ }^{(1)}$ \\ ${ }^{(1)}$ Goddard Space Flight Center \\ 8800 Greenbelt Road, Maryland 20771 USA \\ Email: Cuneyt.Utku@nasa.gov
}

The effect of topography on remote sensing at L-band is examined using the co-located Aquarius radiometer and scatterometer observations over land. A correlation with slope standard deviation is demonstrated for both the radiometer and scatterometer at topographic scales.

The Aquarius/SAC-D observatory was launched on June 10, 2011 and has been collecting data since August 25[1]. Aquarius has three beams with local incidence angles (at boresight) of 28.7, 37.8 and 45.6 degrees. Each antenna beam is shared by an L-band radiometer $(1.4 \mathrm{GHz})$ and scatterometer $(1.26 \mathrm{GHz})$ which have been designed to provide nearly simultaneous views of the same footprint on the surface [2]. Although the goal of Aquarius is remote sensing of sea surface salinity, the radiometer and scatterometer are on continuously and collect data for remote sensing research over land. Research is reported here using the data over land to determine if topography could have impact on the passive remote sensing at L-band.

The effect of topography on microwave emission from land has been discussed in several studies [3-6] and a few studies have also been conducted to experimentally observe the effect of characteristics such as slope on emission [7-8]. Although an impact is predicted theoretically, a major uncertainty in remote sensing from space is the large footprint and the effect of the associated averaging on the net signal. Aquarius provides a unique opportunity to look at the effects of topography. In particular, having both passive and active looks at the same footprint provides corroborative evidence for any suspected signal in the radiometer response.

In this study, we report observations from two study regions: North Africa between $15^{\circ}$ and $30^{\circ}$ Northern latitudes and Australia less the Tasmania Island. Common to these two regions are the semi-arid climate and low population density; both favorable conditions to isolate the effect of topography from other sources of scatter and emission such as vegetation and urban areas. Over these study regions, topographic scale slopes within each Aquarius pixel are computed and their standard deviations are compared with Aquarius scatterometer and radiometer observations over a 36 day period between days 275 and 311 of 2011. The slope standard deviations are computed from the $90 \mathrm{~m}$ Digital Elevation Models (DEM) produced from the Shuttle Radar Topography Mission (SRTM) [9].

Theory predicts an increase in the scatterometer backscatter with slope variance and in the case of the radiometer a decrease in emissivity at V-pol and an increase in H-pol. The scatterometer response is due to the higher probability of backscatter with higher slope variance and the radiometer response is largely due to polarization mixing caused by the local slope. Examples demonstrating observation of these effects in the data are shown in Figures 1 and 2 for the North Africa site. Results for Australia are similar. 
Radiometer observations are shown in Figure 1. Data are shown for the inner Aquarius beam (blue) and the outermost beam (red). In order to remove variability due to changes in surface temperature, the emissivity for each pixel is computed and multiplied with a fixed surface temperature of $300 \mathrm{~K}$ to obtain standardized brightness temperatures. Notice that at H-pol. (left), the brightness temperature increases with slope variance whereas at V-pol (right). the brightness temperature decreases. This is consistent with theory which suggests that the dominant effect is polarization mixing due to large-scale slope. Also notice that the effect is larger for the outer beam than for the inner beam. This is consistent with the larger mean difference between the two polarizations at the larger incidence angle (i.e. brightness temperature at $\mathrm{H}$-pol. decreases with incidence angle whereas it increases at V-pol.). These effects are consistent with simulations using a facet model and the DEM to represent the surface [6].

Figure 2 shows the corresponding results for the scatterometer data. The backscatter coefficient is plotted as a function of slope variance for the North Africa region for the inner (blue) and outer (red) beams for HH-pol. (left) and VV-pol. (right). Unlike brightness temperatures, backscatter increases with slope variance for both polarizations. This is because the higher the slope variance the more likely that the transmitted signal will encounter facets favorably oriented to result in backscatter. Also notice that for lower incidence angle (inner beam) the dependence on roughness is stronger than in the case of higher incidence angle (outer beam). This is likely due to the fact that the slope angles are closer to the incidence angle (with respect to the normal local geoid) for the inner beam hence causing stronger return.

The figures demonstrate a definite trend but with large scatter in the data. Effects such as variation in soil moisture, soil type, vegetation and other factors have not been taken into account and are likely contributing to the data scatter.

The data used in this analysis has been taken without any pre-selection other than applying an RFI filter. Evidence to date suggests that the Aquarius radiometers are working well over oceans and, although the verification is less robust at the present, over land as well. The results presented here agree with the theory and are consistent among the Aquarius beams. However,
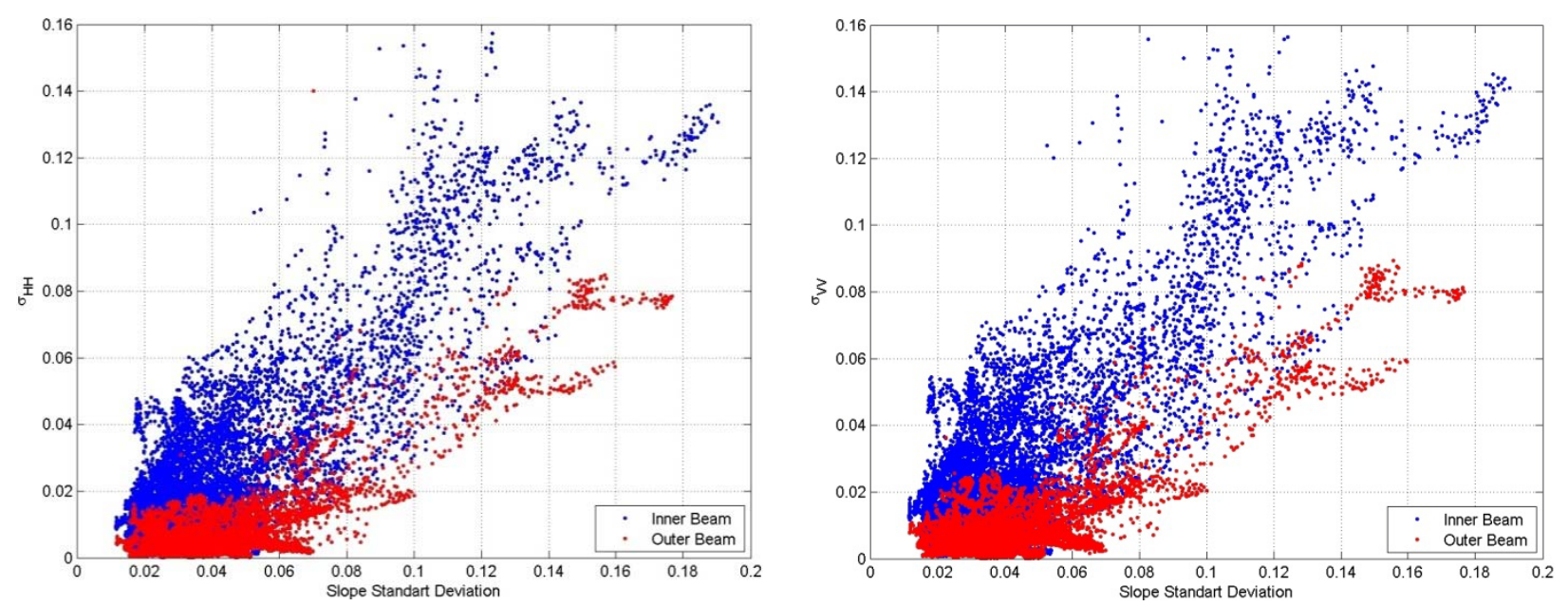

Figure 2. Comparison of inner and outer beam backscattering coefficients vs. slope standard deviation for North Africa (left) HH-polarization (right) VV-polarization. 
there is an anomaly in our results that require further investigation. In particular, normalized values of brightness temperature for the outer beam at V-pol. (e.g. right plot in Figure 1) exceed $300 \mathrm{~K}$ which suggests an emissivity greater than unity. Initial investigation suggests that this is a problem (e.g. bias) with surface temperature data for the North Africa site, but further investigation is needed.

Similar results have been obtained for the Australia region but without the anamoly described above. The presentation will include results from both regions and also a comparison of the data withpredictions of theory.

\section{References}

[1] [Online]. Available: aquarius.nasa.gov/news.html

[2] D.M. Le Vine et al., "Aquarius: An instrument to monitor sea surface salinity from space," IEEE Trans. Geosci. Remote Sens., 45, pp. 2040-2050, 2007.

[3] C. Matzler and A.Standley, "Relief Effects for Passive Microwave Remote Sensing," Int. J. Remote Sensing, 21, pp. 2403-2412, 2000.

[4] A. Mialon, L. Coret, Y.Kerr, J.P.Wigneron, "Flagging the topographic impact on the SMOS signal", IEEE Trans. Geosci. Remote Sens., 46, pp. 689-694, 2008.

[5] M. Talone, A. Camps, A. Monerris, M. Vall-llossera, P. Ferrazzoli and M. Piles, "Surface Topography and Mixed Pixel Effects on the Simulated L-band Brightness Temperatures,” IEEE Trans. Geosci. Remote Sens., 45, pp. 1996-2003, 2007.

[6] C. Utku and D. Le Vine, "Topography Effects on Brightness Temperature in Remote Sensing at L-band”, Proc. XXIX URSI General Assembly, Chicago, Illinois, Aug. 2008.

[7] A. Monerris et al, "Topography Effects on the L-band Emissivity of Soils: TuRTLE 2006 Field Experiment," International Geoscience and Remote Sensing Symposium Proceedings, pp. 2244-2247, Barcelona, Spain, 2007.

[8] X. Li, L. Zhang, L. Jiang, T. Zhao and Z. Hao, "Measuring and Simulating Passice C-Band Microwave Relief Effects over Uncovered Land Surface in Remote Sensing," International Geoscience and Remote Sensing Symposium Proceedings, pp. 3113-3116, Vancouver, Canada, 2011.

[9] [Online]. Available: http://srtm.csi.cgiar.org/ 